\title{
Actresses, Gender, and 1920s Theater in China: A Discussion Concerning “Female Involvement in Art Performances”
}

\author{
LIU Xun-qian \\ The University of Hong Kong, Hongkong, China
}

\begin{abstract}
In 1923, Wu Ruiyan, a schoolgirl at the Beijing People's Art Drama School, starred in a play titled Hero and Beauty, written by Chen Dabei. This was the first joint performance of male and female performers in the history of Chinese drama. The incident immediately triggered a debate in the Morning Newspaper Supplement between a group of middle-class intellectuals concerning "female involvement in art performances”. This paper sees the boom in female participation in politics in the 1920s, as well as the "improvement in traditional drama" during the early republican period in China as the reasons behind the discussion. This incident shows how the New Cultural Movement shaped intellectuals’ views on females and art performances.
\end{abstract}

Keywords: New Culture Movement, Beijing People’s Art Drama School, spoken drama

\section{Introduction}

On June 30, 1923, Wu Ruiyan (吴瑞燕, 1904-1981), a female student from Beijing People’s Art Drama School (北京人艺戏剧专门学校), performed The Hero \& The Beauty (英雄与美人) written by Chen Dabei (陈大悲, 1887-1944). It marked the first attempt of male and female performers jointly appearing in a Chinese drama. Previous scholars mostly regarded this event as a byproduct of the May Fourth New Cultural Movement, and recognized its positive and pioneering significance in the history of Chinese drama.

On July 8, an article entitled Females' involvement in art: An unforgettable night was published by the Morning Newspaper Supplement (晨报副刊)—one of the four major supplements advocating Marxist ideas and introducing Russia's revolution in China—under the pen name of Dongzhi (东枝). In this article, Wu Ruyan's courage of performing on stage was highly lauded, and unexpectedly, the event caused a huge sensation. Why did the public respond so strongly to this event? The occurrences of this event are worth further exploration. So far, the debates on the event have been briefly mentioned only in A Study on the Formation of Chinese Spoken Drama (中国话剧成立史) by Seto Hong (せとひろし, 濑户宏). This paper attempts to further discuss the public discussion aroused by the newspaper, and examines the interpretation of Northern Chinese intellectuals after the May Fourth Movement about female involvement in drama and politics.

\section{Debates on "Female Involvement in Art"}

The debates on female involvement in art were caused by a joint performance of males and females on stage. In the winter of 1922, Pu Boying (蒲伯英, 1875-1934) and Chen Dabei jointly founded Beijing People’s Art Drama School (abbreviated as “People’s Art Theater” 人艺剧专) (Wetmore, Jr., Liu, \& Mee, 2014, p. 97).

LIU Xun-qian, Ph.D. Candidate, School of Chinese, The University of Hong Kong. 
On May 19, 1923, the People's Art Theater held the first public performance in Beijing Xinming Theater(新明剧场). The list of plays included Words Fail Me (说不出), a one-actor dumb-show, and The Hero \& The Beauty by Chen Dabei. Set against the Revolution of 1911, The Hero \& The Beauty depicts the transformation and remorse of Zhang Hanguang (张汉光), a revolutionist, and his mistress, Lin Yaqin (林雅 琴). Lin is a student who is unsatisfied with a marriage arranged by her parents. In protest, she leaves her home and meets Zhang. Zhang seeks refuge in Japan, while Lin is reduced to an unlicensed prostitute. Eventually, Xiao Huanyun (萧焕云), Chief Inspector of the Qing government, becomes Lin's new lover. Later, the Revolution of 1911 succeeds and Zhang is selected as the Governor. Lin thus pretends to rekindle her relationship with Zhang, and asks Xiao Huanyun to pretend to be her elder brother and serve as Zhang's adjutant. Unfortunately, Zhang is framed by Lin and Xiao, and sent to prison. After this episode, Lin and Xiao run away with Zhang's fortune. In the process, Xiao attempts to plunder the fortune. He shoots and kills the foster mother of Lin, while he himself is later shot to death by Lin. At this moment, Wang Jianren (王建人), a colleague and good friend of Zhang Hanguang, chases, catches, and then shoots Lin Yaqin to death. Lin is guilty before her death, and proves Zhang's innocence. Zhang later commits suicide for his repentance. Chen Dabei, the play writer, aimed at conveying a lesson to the audience by using exciting plots, which to some extent are hard to believe. Although the entire story sounds rather farfetched, it was an extremely popular new play during that time (PEI, 1928, pp. 25-26).

In the show on May 19, 1923, Wu Ruiyan, the only female in the People’s Art Theater, was chosen as the female protagonist for The Hero \& The Beauty. In this play, there are only two female roles, namely Lin Yaqin and Lin's foster mother. In the first show, Lin's foster mother was acted by a male performer. It was not until the sixth public performance on June 30 that the performers and the characters in the play were fully matched in terms of gender, along with more and more female students seeking to study art at the People's Art Drama School. It was until then that the joint performance of male and female roles on stage was realized in a real sense.

On July 8, Morning Newspaper Supplement carried an article entitled Females' involvement in art: An unforgettable night by Dongzhi. It spoke highly of Wu Ruiyan's courage on stage. Four days later, Shen Zhaotang (沈召棠) from Beijing, and Xu Hegao (徐鹤臬), a student from Nankai School, both wrote articles praising Wu's performance. At the end of the article by Dongzhi and Shen Zhaotang, they even directly exclaimed, “Long Live Miss Wu Ruiyan”.

In fact, this was not the first time that the People's Art Drama School held a performance with males and females performing together (Ferris, 1993). The difference of The Hero \& The Beauty was that Wu gave full expression to the female character. More specifically, on stage, she highlighted her gender, succeeding in improving the artistic level and performance of the entire play. Here, The Hero \& The Beauty performed by the Beijing Experimental Drama Club (北京实验剧社) can be used as a comparison, in which Lin Yaqin was performed by a male performer, Feng Zhimo (封至模, 1893-1974). Some audiences spoke highly of Feng’s "graceful movements', which represented a consummate performance of a male acting a female role. That being said, he wore make-up which was too heavy. This was irrelevant from the macroscopic features of Lin Yaqin being reduced from a student toa prostitute. Conversely, Xu Hehao praised Wu Ruiyan's performance by saying that, "In the last scene, the pathetic look and sound of Lin Yaqin, after shooting Xiao Huanyun to death, will remain in audiences' mind forever. It also tells us that a male cannot perform a female role so realistically 
and touchingly”. Li Zongtong (李宗侗), an audience member, also pointed out that, “In terms of performers, Wu Ruiyan and Hu Xiaotian (胡笑天, performer of Xiao Huanyun, also a student of the People's Art Drama School) are the best. Cai Fangxing's (蔡芳信) faked voice (a male student of People's Art Drama School) is overshadowed by Wu's natural sound”. Another audience member, “Xuanmin” (轩民), also commented that, "Lin Yaqin starred by Miss Wu does not look too elegant. This is just what the play is depicting. In the fifth scene, Lin repents for what she did before her death. Many audiences are touched by this scene, feeling as if they are experiencing the scene in person" (Xuan, 1923).

\section{The May Fourth Debates on Theatre Reform}

The following section is a brief introduction of the ideological background of three writers-Dongzhi, Shen Zhaotang, and Xu Hehao. Their articles were not published at the spur of a moment, but out of their persistent ideological stance with striking era characteristics.

The May Fourth New Cultural Movement, beginning in the mid-1910s, is widely considered as China's initiation into modernity. The May Fourth intellectuals' proclamation for theatre reform gave birth to the modern Chinese theatre from huaju (话剧), or spoken drama, which is the Chinese generic description for dialog plays in the Western style (Chou, 1997, pp. 16-38).

The May Fourth theatre was formally launched in June 1918 when New Youth (新青年) issued Hu Shi’s (1891-1962, 胡适) Yibusheng zhuyi (Ibsenism 易卜生主义), translations into Chinese of Ibsen's A Doll House (玩偶之家), as well as a brief biographical introduction to the Norwegian playwright. Hu's advocacy of Ibsen initiated a series of discussions on theatre reform. Four months later, New Youth issued a special number, in which writers from various backgrounds joined $\mathrm{Hu}$ Shi and argued fervently about the problems of traditional forms and how best to modernize traditional Chinese theater. Their ideas about theater reform were primarily based on their observations of Western theater evolution. For example, in Literature Evolution \& Theater Reform (文学改良刍议与戏剧改革), Hu Shi proposed that theater should change in accordance with social-cultural development, and that any country's artistic reform should be consistent with the reform of the larger global community. The close connection between theater and society was increasingly highlighted around the May Fourth Movement. An increasing number of intellectuals stood out to request abandoning traditional Chinese drama and replacing them with new Western drama. New Youth was a representative that held this view. To summarize, the advocacy of the Literature Evolution \& Theater Reform appeared after the 1900s. In the 1910s and the 1920s, more and more intellectuals joined the advocacy.

Chinese theater performance was started as an extracurricular hobby by students. Take Nankai School for example; it ushered in a new trend of theater performance, and had a long tradition in the field. The Nankai School in Tianjin started their xinju activities in 1909, and founded the Nankai Xinju Group in 1915. This group became the center of Northern China's spoken drama movement.

Shen Zhaotang was a graduate of Nankai School. So far, one can still find records of Shen's participation in Nankai School's theater club in 1918 (CUI, XIA, \& LI, 1984, pp. 16-17). This could probably explain his admiration of Western theater after graduation and his passion for drama translation. Xu Hehao was a student living in the Xicheng District, Beijing. He mentioned that during a winter vacation in1922, "several classmates issued a small magazine”, in which he wrote an article criticizing traditional Chinese theater. Shen and Xu's attention to the development of theater in China could not be separated from the atmosphere and education of their school. 
Dongzhi was a pen name, and its actual identity is still unknown. However, from the existing newspapers and magazines, an ideological stance of Dongzhi can be generally outlined. He self-claimed that, "I worshipped Confucius in the past, then Liang Qichao, and Hu Shizhi recently”. This revealed Dongzhi to be a youth influenced by this new ideological trend during that period.

One month before, Dongzhi praised Wu Ruiyan and lambasted traditional Chinese opera. In April 1923, Xu Zhimo (徐志摩, 1897-1931) and Chen Xiying (陈西瀅, 1896-1907) eulogized Mei Lanfang (梅兰芳, 1894-1961), a representative of the traditional theater, and offended the new theater circle, which triggered a fierce debate between the two sides (MIN, 2012). On June 7, Dongzhi published Mei Lanfang and Art (梅兰芳 与艺术) in the Morning Newspaper Supplement, disproving Chen Xiying's judgment of Mei Lanfang to be China's Shakespeare. Dongzhi pointed out that traditional theater is not a form of art. He questioned rhetorically, "I am wondering whether there is an art called males playing female roles or male artists engaging in performing female roles. Chen Xiying should well know that, apart from music, paintings and carvings, there is also an art called 'males performing female roles". As a result, Dongzhi felt proud and elated for the new theater, whilst also praising Wu Ruiyan with great exclamation. Wu's performance allowed a play to have the right role played by the right gender. This was a sharp contrast from the form and performance of traditional opera, and also a striking advantage of the theater. Xiong Foxi (熊佛西,1900-1965), a famous dramatist once said,

I want to ask friends who are fond of watching traditional operas: Do you know whether Mei Lanfang practices all day wrong? Is he a Xiaodan singing and performing in the traditional opera or does he look like a female? Though he tries hard and practices every day, the effects are still far from satisfactory. Thus, it is hard for performers to play roles opposite to their gender. Even efforts can hardly help them achieve performance. (XIONG, 1922, pp. 9-14)

The intellectual origin for Dongzhi's advocacy of the new drama was probably from New Youth, the magazine operated by Hu Shi. In the opinion of Dongzhi, China's traditional theater could not be defined as an art, and it was not worth watching. Dongzhi's ideas coincided with HuShi's "A call to theater reform".

To summarize, in terms of social response, Wu Ruiyan's performance was recognized by Dongzhi, Shen Zhaotang, and Xu Hehao. A question may be asked—why were debates triggered over the event?

\section{Ideas of Opponents}

In fact, disputes on Dongzhi's article, Females' involvement in art: An unforgettable night, were not groundless. While singing praises of females' involvement in art, he also devoted a large paragraph to persuade females into giving up their participation in political affairs.

There were two waves of female political participation movements. One was caused by ambiguity on stipulations on rights in Provisional Constitution of the Republic of China in the early years of the Republic of China (1912-1949). At that time, feminist ideas had not yet been fully spread. Due to a lack of support, the movement was quickly subsided. The other movement took place between 1921 and 1923. Political circles felt that national constitution was at a far distant date, and they proposed formulating the provincial constitution first. In response to the proposal, females advocated that gender equality should be included in the provincial constitution. This aroused a widespread female political participation movement. When the background isconsidered, one can better understand what Dongzhi said in his article, "In a society where females are so degraded and even they themselves deny their own personality, we can also hear a few protests among the crowd of silent females. This is the so-called appeal to 'females' involvement in politics'” (Dongzhi, 1923, pp. 4). 
However, Dongzhi did not side with the movement upholding “females' participation in politics". He thought that, to females, involvement in education was far more important than involvement in politics, and involvement in art was far more important than involvement in education. That was why he hoped that females could replace "their participation in art" with "participation in politics".

Objectively speaking, Dongzhi's emphasis on females not being "involved in politics" was not to purposely belittle females, but to show his utmost disappointment about the chaotic political circles lasting for nearly 12 years after the Revolution of 1911. He said, "Results of political participation are visible. Male representatives have ruled for 12 years, and the dictator, Yuan Shikai (袁世凯, 1859-1916) comes in power. Thus, even if female representatives come into play in the political circle, chances are low for things to take a turnaround”. Between the lines of Dongzhi's article, one can feel Dongzhi's disappointment and disgust about the Northern Government (北洋政府).

Dongzhi identified the essence of politics as "a fight for an extravagant life and for more powers and interests". He held a utopian hope about art. Deep down, he believed that, along with the progress of human civilization, "all the internal and foreign affairs, which are important at present, will be reduced into 'a senseless play”, By then, "the whole part of humans' life will be devoted to artistic creation and artistic appreciation”. Dongzhi's admiration of art and education was not rare among youths of the May Fourth Movement, who deeply appreciated Western culture. His pessimistic outlook on politics was also representative. However, his advocacy of replacing "females' participation in politics" with "females' participation in art" aroused the dissatisfaction of feminists.

After one week, an article was submitted to the Morning Newspaper Supplement under the title of Why Can't Females Participate in Politics? Xu Qinwen (许钦文, 1897-1984), author of the article argued, “Of course, females should participate in art, but it also makes sense for their participation in politics”. His reason was quite simple. If females could participate in politics and be appointed as officials, their parents holding high official positions and wealth would be more willing to provide their children with better education, and fewer females would be deprived of their right to receive education.

Xu Qinwen was originally from Shaoxing, Zhejiang. Influenced by the ideological trend of the May Fourth Movement, he worked and studied in Beijing in 1920. Thanks to support of Sun Fuyuan (孙伏园, 1894-1966), his fellowman and an editor of the Morning Post (晨报), Xu could frequently publish novels and articles in the Morning Newspaper Supplement. Moreover, he was a keen reader and contributor of Women's Magazine (妇女杂志) (Nivard, 1984), and kept a close eye on two issues—women’s education and women’s rights, which could not be separated from the tragic suffering of his 12 sisters. He thought that "as long as females take higher education, they can get on their feet even if their husbands do not treat them well”. Therefore, emphasis on female education and promotion of female involvement in politics was a consistent proposal of Xu Qinwen.

As stated above, Dongzhi and Xu Qinwen were both intellectuals baptized by the New Cultural Revolution and the May Fourth Movement. However, they were still deeply divided in terms of their ideological stance. Dongzhi advocated art but demeaned politics; while Xu Qinwen was deeply concerned about female rights. The proponents and the opponents in the debates could not simply be divided into radicals and conservatives. Instead, they held different new ideas. This resulted in their disagreement on whether females should participate in art or politics. The disagreement was also a major cause of their debates. 
Similar to Xu Qinwen, 'Alv', a student of Nankai School, also protested against Dongzhi's article published in the Morning Newspaper Supplement. Alv was Wu Ruiyan's friend,and vigorously supported his friend's performance career, but objected to the articles of Dongzhi and the other two, regarding their behavior as adulation on a new-type of newspaper.

His protest was based on two reasons: First, in many girls' schools, drama performance had been nothing new. In traditional operas, there were also actresses. Wu Ruiyan was not the first female involved in an artistic performance in China. To praise her achievements as the start of "females' involvement in art" was an exaggeration. Second, concerning Xu Hehao's praise of Wu Ruiyan for her full expression of the identity and manner of characters, such as Zhen'er in Miss Youlan (幽兰小姐) and Xu Huixiu in Persistence of Moralization (维持风化), Alv thought that "there is nothing to praise for a performer to make herself be the character in a drama”. More specifically, Alv hoped that female performers should be judged by the same standards as male performers. Blind praise was suspicious of flattering, which was actually not beneficial to encourage more females to perform in dramas.

Yu Xiezhong (余协中) also expressed his opinions on this case. He was the father of the historian, Yu Yingshi (余英时). In 1921, he studied in the Department of History in Yanjing University. He also sided with Alv, stating that "We should eulogize the impression given by the theater and performance of the theater", rather than shouting hooray to female actresses.

As a defense, Shen Zhaotang clarified that "females' participation in art" was not exaggerating. In his opinion, "participation in art" referred to participating in real 'art'. The current "traditional dramas" and the “dramas performed only in girls' schools” were far from satisfactory. In order to refute this idea, Alv wrote articles, saying that "Shen Zhaotang and I both do not regard the traditional drama in which both females and males perform is the art required by us, but I believe that the traditional drama has its artistic value". Thus, it could be seen that, in the ideological trend of drama reform, Shen Zhaotang proposed complete replacement of Western dramas by traditional dramas. Alv showed sympathy for Chinese traditional drama. He wanted to reform traditional drama rather than to fully abolish it. The two sides debated with each other based on different ideological resources.

It was quite obvious that Alv was not an opponent of "joint performance of females and males". He questioned this mainly out of his preventative and vigilant psychology. After all, adulation was regarded as a bad habit of the traditional theater in Beijing. It was the greatest taboo in the new drama circle. In the premiere of The Hero \& The Beauty on May 19, Chen Dabei required audiences to respect the theater by not applauding or speaking loudly at the opening. After watching the play, audiences were invited to criticize it practically and realistically instead of being a new-type of flatterer. Therefore, Alv wrote this paper as an attempt to eliminate the backwards tradition of 'adulation' in traditional theater, and to highlight the elegance and progress of the new-type of theater.

\section{Conclusion}

Female participation in art in 1923 was an issue regarding art and gender emerging from public discussions about a newspaper supplement after the May Fourth Movement. These discussions were enlightening in terms of their social and educational significance. Intellectuals' participation in discussing public issues encouraged an interaction between editors and readers, as well as between the readers themselves. This not only aroused public attention, but also encouraged people to participate in discussions and convey new 
interpretations of stage gender to readers. This was also a striking characteristic of the May Fourth Movement.

Based on the above analysis, the contributors widely recognized the right of females to act. They encouraged actresses to give full play to their special qualities. With actresses performing in female roles, the performance effects and artistic value was improved, and more females could become involved in art (Chou, 1997, pp. 130-152). From the dominant practice of all-male casting, to allowing female artists to perform their own roles and strike their own poses on the Chinese stage, the transformation partially reflected the transformation of the Chinese intellectuals' cognition of stage gender. Undoubtedly, it could not be separated from the women's emancipation movement in the May Fourth Movement. Moreover, it partially reflected the baptism of the May Fourth Movement and the New Cultural Movement of intellectuals.

The debates regarding female participation in art was in essence a representation of the internal ideological difference of a new culture. Young students and intellectuals gathered out of interest in art-related topics. However, their opinions varied based on issues such as theater reform and female participation in politics. These opinions were a result of taking on different ideological resources and concept tools from the New Cultural Movement. Apart from their consensus on females' right to perform, they also had disagreements. The seemingly trivial details above demonstrate not only how the new ideas of the May Fourth Movement were spread among intellectuals, but also the "selective" differences of young intellectuals' interpretation and acceptance of this new ideological trend.

\section{References}

Chou, H. -L. (1997). Striking their own poses: The history of cross-dressing on the Chinese stage. The Drama Review,41(2), 130-152.

Chou, K. H. -L. (1997). Staging Revolution: Actresses, Realism \& the New Woman Movement in Chinese Spoken Drama \& Film, 1919-1949 (unpublished Ph.D. Thesis, New York University, 1997).

CUI, G. L., XIA J. S., \& LI, L. Z. (1984). The historical resources of Nankai School’s Xinju Activities from 1909 to 1922 (南开学 校话剧运动史料). Tianjing: Nankai University Press.

Dongzhi (1923). Females’ involvement in art: An unforgettable night, Morning Newspaper Supplement, 8 July.

Ferris, L. (1993). Crossing the stage: Controversies on cross-dressing. London: Psychology Press.

Hong, S. (2005). A Study on the formation of Chinese spoken drama. Tokyo: Toho-shoten.

MIN, T. (2012). Mei Lanfang and the Twentieth-Century international stage: Chinese theatre placed and displaced. New York: Palgrave MacMillan.

Nivard, J. (1984). Women and women's press: The case of the ladies' journal (Funu Zazhi) 1915-1931. Twentieth-Century China, 10(1), 37-55.

PEI, L. (陪良). (1928). Chinese drama review (中国戏剧概评). Shanghai: Taidong Publishing House (上海泰东书局).

Wetmore, Jr., K. J., Liu, S. Y., \& Mee, E. B. (2014). Modern Asian theatre and performance 1900-2000. London: Bloomsbury Methuen.

XIONG, F. X. (1922). I hope that the students' troupe will perform joint performance of male and female performers (我希望学生 新剧团实行男女合演). Theatre (戏剧), 2(4), 9-14.

XU, X. Q. (2014). Cosmopolitanism, nationalism, and individualism in modern China: The Chenbao Fukan and the new culture era, 1918-1928. New York: Lexington Books.

Xuan, M. (1923). After watching The Hero \& The Beauty. Morning Post Supplement, 9 July. 